\title{
APPLICATION AND CHARACTERISTICS OF WATERBORNE ROAD MARKING PAINT
}

\author{
Darko Babić ${ }^{1}$, Tomasz E. Burghardt ${ }^{2}$, Dario Babić ${ }^{3}$ \\ ${ }^{1,3}$ University of Zagreb, Faculty of Transport and Traffic Sciences, Vukelićeva 4, 10000 Zagreb, Croatia \\ ${ }^{2}$ M. Swarovski Gesellshaft m.b.H., Industriestrasse 10, 3300 Amstetten, Austria
}

Received 21 November 2014; accepted 14 January 2015

\begin{abstract}
Horizontal road markings are one of the essential safety features of modern roadways. All of the utilised systems consist of a pigmented coating containing partially embedded retroreflective elements such as glass beads. In addition to durability and functionality of the road marking, ease of application and effect on human health and environment are primary considerations for their selection. Road marking systems can be divided into plural component materials that cure due to chemical reaction occurring at the site of application, thermoplastics that require heat for application, and paints, drying upon evaporation of the dissolving medium. The focus of this paper is on road marking paints with a special emphasis on contemporary waterborne materials. Over 100 years old solventborne technology furnishes paints that afford consistent application properties under a variety of conditions such as lower temperatures and high humidity. Their environmental and human health impact is significant and durability quite poor. Modern waterborne paints are based on acrylic resins and incorporate developed in the 1990s quick-set chemical mechanism for drying. Under favourable weather conditions, they dry faster as compared to solventborne. However, their known weakness is risk of washout in case of rain and sluggish development of washout resistance at marginal application conditions like high humidity and low temperature. Impact of waterborne paints on human health and environment is very significantly minimised as compared to other materials. Their durability is significantly higher as compared to solventbased paints. Analysis of characteristics of waterborne road marking paints and preliminary results from their trial application in Croatia are presented herein. Based on the presented comparison with solventborne materials, after results from test application become available, intelligent decisions regarding future use of waterborne road marking paints in Croatia and other countries that have not embraced this technology shall be possible.
\end{abstract}

Keywords: waterborne road marking paint, road markings, traffic paint, solventborne road marking paint, retroreflection.

\section{Introduction}

In 2011, 25726 people died on the roads of the European Union and 1115410 persons were injured (European Road Statistics, 2013). One of the international efforts is reduction of these numbers by $50 \%$ before 2020 ("Towards a European road safety area: policy orientations on road safety 20112020"). The corresponding social cost was approximately 130 billion Euros (European Commission, 2010).

Horizontal road markings are one of the safety features on modern roads; their influence on driving safety is especially

${ }^{1}$ Corresponding author: dbabic@fpz.hr 
prominent at night and in adverse weather conditions (Migletz et al., 1994). The markings can be defined as a set of longitudinal and transversal lines, signs and symbols on the surface of transportation infrastructure. They represent a fraction of overall traffic signalisation and cannot be at present replaced by other means. Studies shown that generally, the presence of only centre and edge lines can reduce all accidents by $20 \%$ (Miller, 1992).

Efficiency and durability of road markings are required by both road users and the road authorities. From the users' point of view, road markings provide an optical path by means of contrast of colour and luminance with the road surface and it appears that these properties should be maximised (Horberry et al., 2006). Selection of the type of road marking materials by road administrators depends on many factors, including the desired durability, required visibility, price, and local considerations. Considerable funds are allocated to keep the markings at adequate performance level. Even though the overall long-term performance and cost should be balanced, unfortunately, quite frequently it seems that short-term expense plays more significant role. ${ }^{2} \mathrm{~A}$ model could be functional contracts, such as are in place for example in Finland, where the application company is paid for maintaining the retroreflectivity and the choice of materials is in its hands. Environmental friendliness is also critical: not only in terms of contents of emissions of Volatile Organic Compounds (VOC), but also as an overall impact on our planet. Green Public Procurement (GPP)

${ }^{2}$ In Croatia, public tenders have condition that the price is the only consideration, according to the "Law of Public Procurement", Article 58, Paragraph 1b. criteria for outdoor paints and varnishes is extended to road marking materials as well. ${ }^{3}$

Assessment of effects of various road markings has not produced definitive results as to which road markings maximise safety benefits (Asdrubali et al., 2013). Field of driver attention is changing depending on the construction characteristics of the road, the traffic conditions, and the vehicle speed, generally decreasing with increase if the speed and increasing when reducing speed (Thurston, 2009). Studies showed that with high visibility markings on outer roads the drivers tend to increase speed, thus nullifying the benefits on safety (Retting et al., 2000). At urban level, things get more complicated because of factors like pedestrian crossings, turnabouts, stop signals and also a different way of driving (Retting et al., 2000). It was also demonstrated that removal of all horizontal markings in low-speed residential areas in a "shared space" concept lead to increased safety for all due to drivers paying more attention on surroundings and other road users instead of following the guiding path (Hamilton-Baillie and Jones, 2005; Experiment done in town of Drachten, 2007; Bosley, 2007).

\section{The Role of Road Markings}

Road markings are one of the most important components of traffic signalisation because of their position in the central area of drivers' attention. Their function is to warn drivers about conditions of the road and its construction characteristics and to help in determining lateral or transverse position of

${ }^{3} \mathrm{GPP}$ for road marking materials is included in "European Commission Decision establishing the ecological criteria for the award of the Community eco-label to outdoor paints and varnishes." (2009/543/EC) Official Journal of the European Union, L $181 / 27$; 14.7.2009. 
their and other vehicles. Important feature of road markings is their continuity along the entire length of the road, which is a significant fact in the process of orientation. It can be said that road markings are telling the driver, with a specific language, what to do and how to behave in certain situations in traffic. They are especially beneficial in poor visibility conditions. The main tasks of road markings are:

- Drawing attention to the situation around and in the area in front of the vehicle, which requires special attention and caution.

- Ensuring traffic management, particularly at approaches to intersections.

- Defining the road in its course and layout.

- Giving drivers clear orientation and safe guidance by day and night.

- Informing drivers about certain legal restrictions.

- Helping to regulate traffic flow in an optimal way.

- Helping drivers to safely reach their destinations.

All drivers interact with environmental clues during driving. Indeed, driving is a series of decisions based $90 \%$ on visual clues (Thurston, 2009). As the overall society age increases, it becomes increasingly important that road systems incorporate sufficient tolerances that cater for deteriorating light perception and also for the longer time it takes for the elderly to react to all of these important visual clues (Zwahlen et al., 1998; Eby et al., 2008).
Two important factors describe connection between driver and road markings:

- A driver must be able to see road markings at a certain distance to perceive, process, and react to the information that the pavement marking presents in order to receive adequate information to safely guide the vehicle. Since the required distance increases as the speed of the vehicle increases, it is often described as constant preview time.

- "It has been established that for night time low-beam conditions, a driver requires a minimum recommended preview time (comprising both eye fixation time and driver reaction time) of 3.65 seconds at $80 \mathrm{~km} / \mathrm{h}$, of oncoming road geometry to enable safe negotiation without the driver requiring to shift attention away from the road, to look for other clues." (Zwahlen et al., 1998)

The contrast between white (in some countries also yellow) marking and black road surface is sufficient at daylight, but at night retroreflectivity plays more significant role. Visibility of road markings at night is accomplished by materials like glass or ceramic beads, which reflect the light from vehicles headlights, as show in Fig. 1 (Migletz et al., 1999). Proper embedment of the reflective elements is critical for retroreflectivity (Grosges, 2008).

A cross-section cut shown in Fig. 2 shows also anti-skid particles and completely sunk glass beads. 


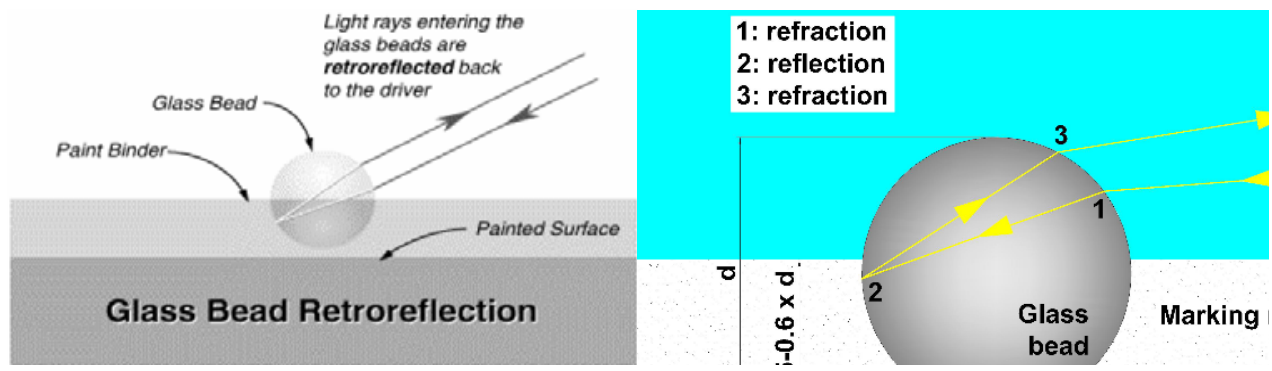

Fig. 1.

Retroreflectivity of Glass Beads in Road Marking

Source: Asdrubali et al. (2013)

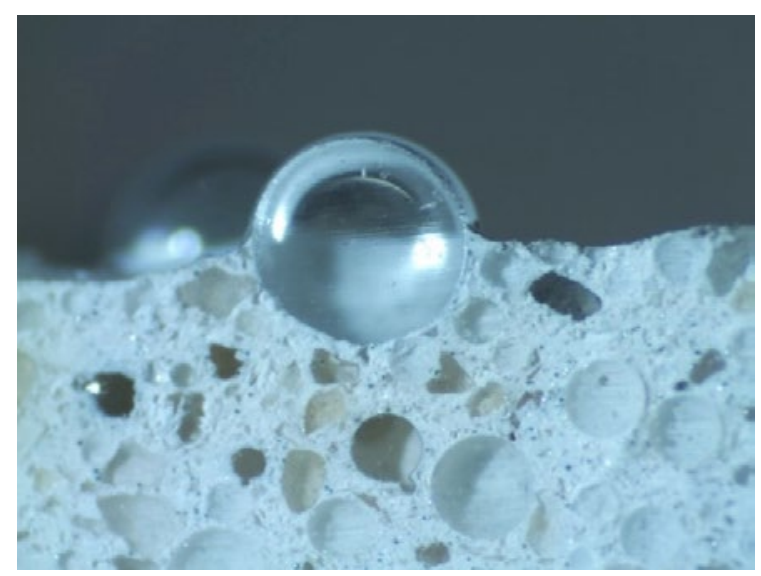

Fig. 2.

Cross-Section of a Well-Embedded Glass Bead

Source: By Authors

Poor visibility of most markings at night during rainy conditions is caused by water blocking retroreflection, as shown in Fig. 3. This deficiency can be alleviated by utilisation of structured markings and large glass beads, which do not become submerged during normal rain conditions. Retroreflectivity is achieved as long as the reflective elements remain properly embedded - upon their loss or imperfect embedment, only daytime reflectivity is maintained. 


\section{Mirror or Specular Reflection}

\section{Water}

\section{Marking Material}

\section{Fig. 3.}

No Retroreflectivity of Glass Beads under Water

Source: Swarco Brochure: Reflective Glass Beads

Retroreflectivity is better if the driver is sitting lower, because the observation angle is smaller, as demonstrated in Fig. 4. Observation angle is important because retroreflective light is returned as a narrow cone with the inner part of the cone being most intense. Therefore, the light appears brighter to a normal car driver sitting lower and nearer to the headlights, than to a lorry driver who sits higher above the headlights.
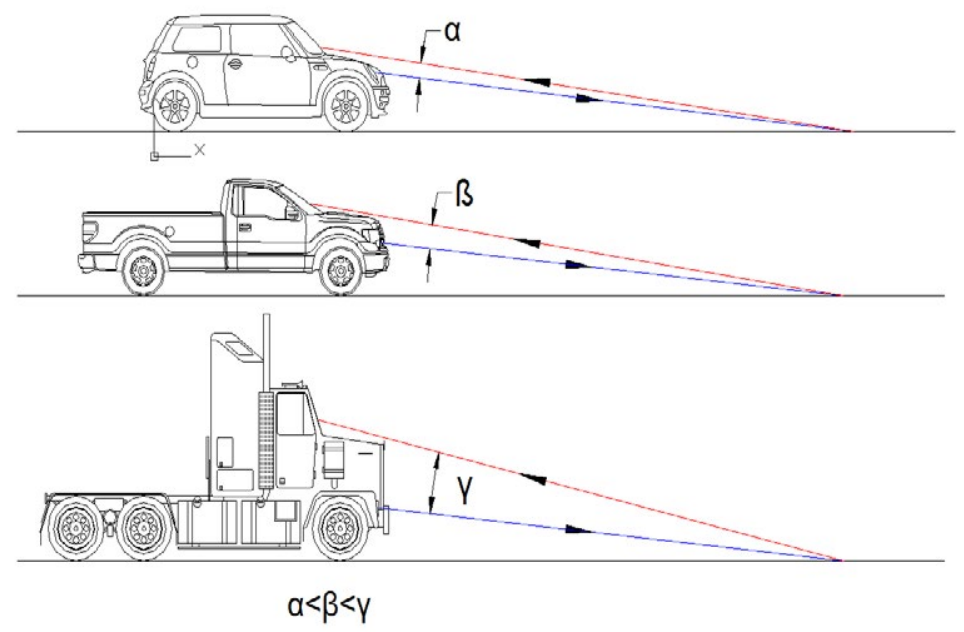

Fig. 4.

Angles of Observation in Different Types of Vehicles

Source: Company $3 M$ Materials 


\section{Materials for Road Markings}

The available plethora of road marking materials is quite difficult to unambiguously classify. Assigning to categories based on the material type - paint, thermoplastic, plural component systems, and tape is rather frequent. Another method is based on the solvent: Solventborne, waterborne, and solvent-free. Yet another categorising is based on their durability, into conventional, durable, and temporary marking products. Dividing road markings types based on their chemistry is also possible and frequently employed. Types of achieved retroreflection under rainy weather is yet another classification method.

Road authorities could also divide the marking systems based on the initial or overall expense of application and maintenance; indeed, some data sources list durability and relative prices of various road markings (Montebello and Schroeder, 2000). Even though such information can serve as general guideline, one must remember that only side-by-side comparison could provide reliable scientifically valid information. (Simultaneously, such comparison would not necessarily be fair due to different typically applied film builds and design of different materials for particular layer thickness.) No references of such comparisons could be found. Even homologation in Germany, run under strictly controlled laboratory conditions, falls into the dissimilar film thickness issue. Hence, all comparisons have to be taken with a grain of salt. Comprehensive cost-benefit analysis that would include all of the cradle-to-grave factors, including also financial and social costs, is still to be done. Overall, one must remember that due to various surfaces and climates, there is never a definite answer (Gates et al., 2003; Dwyer et al., 2013).

Table 1 shows the summary of the road marking materials and attempts their assignment to different categories. Different classes of materials, with particular attention paid to paints, are reviewed below. 


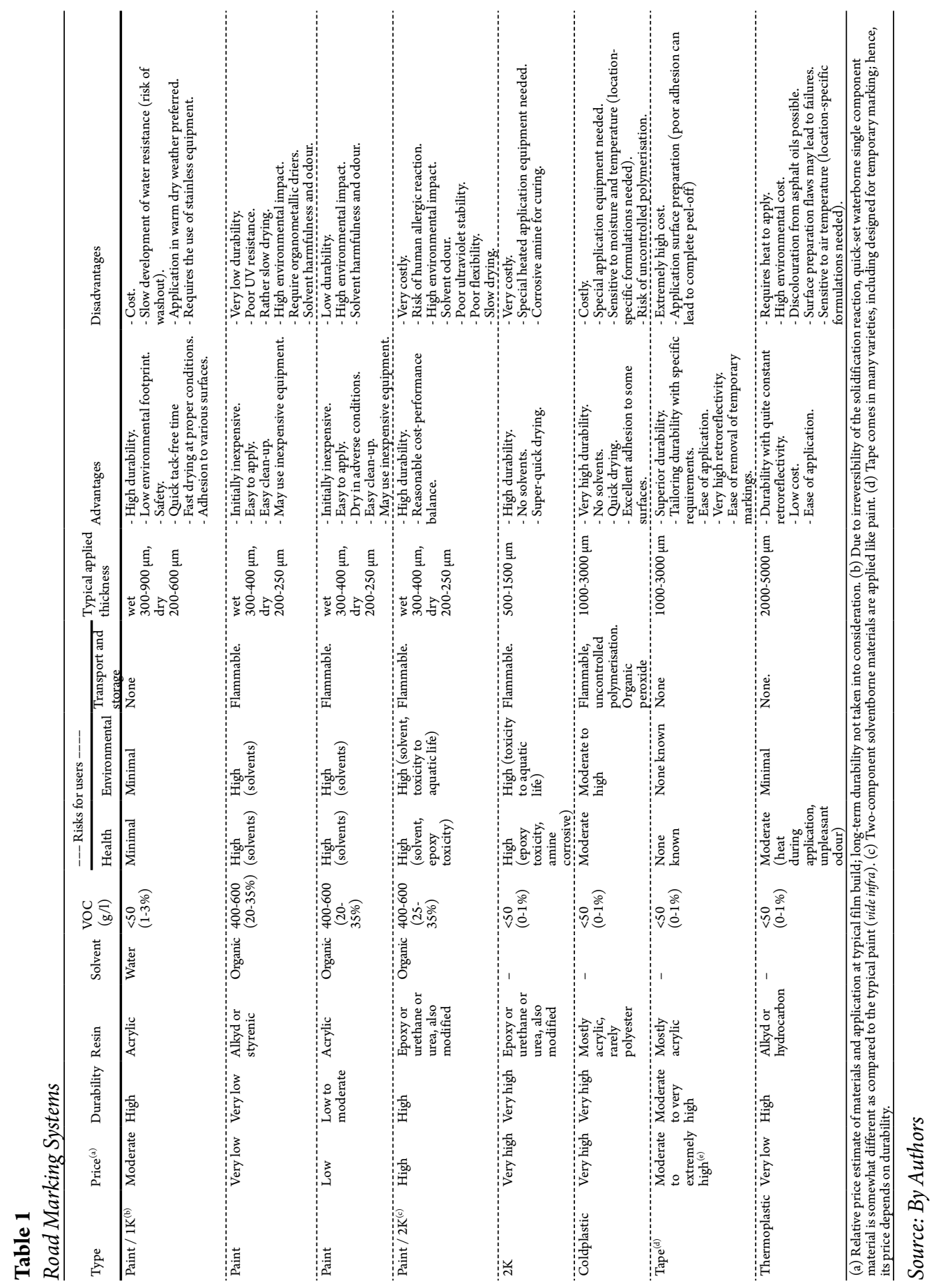




\subsection{Thermoplastic}

Thermoplastic road marking materials were developed and patented in the United Kingdom by R. S. Clare \& Co. Ltd of Liverpool, England in 1933 (Clare, 2015). They remain one of the most successful road marking materials still in use, despite being an 80 years old technology. It should be noted that term 'thermoplastic' has in road marking context different meaning than in chemistry of polymers - these are merely plastic masses, barely modified by polymerisation, that require thermal energy for processing.

Thermoplastic road marking materials are composed of a solid hydrocarbon or alkyd resin intermixed with pigments and fillers as well as glass beads. The resins come either from natural renewable resources, plantations of pine trees, or from petroleum distillates.

Manufacturing of thermoplastic masses is done at high temperature and then the materials are either dried and palletised or pre-formed to the desired shape of special road markings. Application simply requires re-heating of the thermoplastic to about $200{ }^{\circ} \mathrm{C}$ to melt it - it can be done by heated extruding or in case of preformed marking by heating with a torch. Process of thermoplastic road marking materials is shown schematically in Fig. 5 . Thermoplastics are used for line markings, pedestrian crossings, and various signs on road surface.

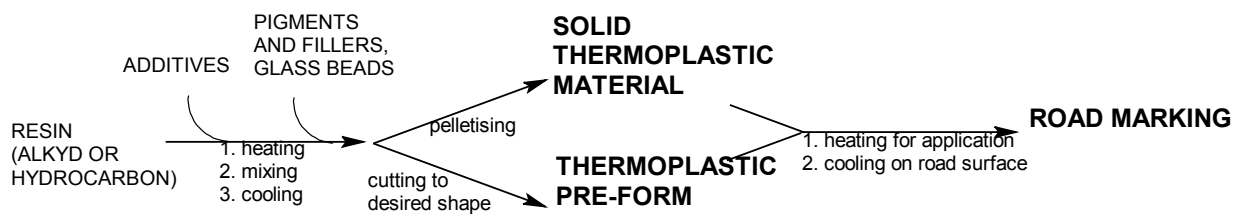

Fig. 5.

Process of Thermoplastic Road Marking Materials Source: By Authors

At application time, additional glass beads and anti-skid materials are dropped-on to assure good initial retroreflection and low surface slip. Proper preparation of the application surface is critical as imperfect adhesion may lead to peeling off and complete loss of material. Thermoplastic materials are modified for the use in specific climates and any mismatches lead to inferior performance.
Thermoplastic materials are essentially solvent-free and some of the resins are from renewable natural resources, but the need to heat them two times significantly increases environmental impact.

Typical application thickness of $3 \mathrm{~mm}$ assures long service life, even in highly used motorways reaching 2-4 years. As the material wears off, intermixed glass 
beads progressively become exposed to the traffic, which allows for maintaining high retroreflectivity throughout the usable life.

\subsection{Two Component Systems: Epoxy, Urea, Urethane, and their Modifications}

With plural component systems, chemical reaction that occurs at the application site assures formation of very durable markings, usable for up to 5 years even on major roads. In these systems, one of the components contains solubilised resin, pigments and fillers and the other the catalyst. In this context, word 'catalyst' denotes merely "component B" and not a catalyst in chemical meaning of the word. Component $\mathrm{B}$, in case of epoxy systems polyamine, is typically not pigmented, but it can be. General process is as shown in Fig. 6. Such materials are used mainly for line markings.

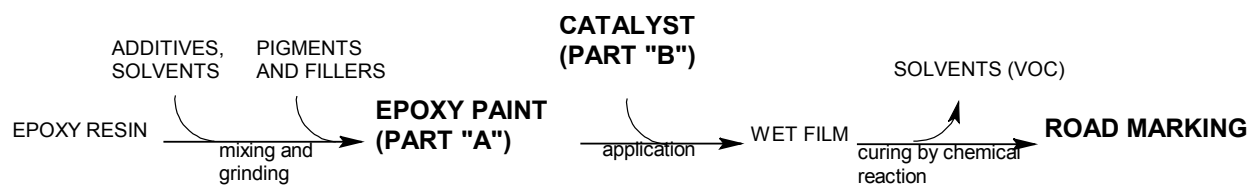

Fig. 6.

Generic Epoxy-Based Materials Process

Source: By Authors

Because epoxy resins are very viscous, the use of solvents is common: VOC content of such epoxy paints is high and can reach even $600 \mathrm{~g} / 1$. Due to generally sluggish reaction that might take even hours after application, pre-mixing in application tank is at times possible. All epoxy systems are formulated to obtain easy mix ratios like 1:1 or 1:2. Epoxy systems are not flexible, but hard and very durable. Typically, they have high affinity for glass beads, which increases usable life of the applied road markings. Their drawback is quite poor resistance to ultraviolet radiation, which causes yellowing: Indeed, applied epoxy road markings must be constantly exposed to traffic to avoid visible discolouration. They can be successfully applied at various conditions, in extreme cases even on slightly moist road surfaces!
More recently developed systems include multi-functional modified epoxy resins and can be formulated as solvent-less systems furnishing drying times as quick at 5 minutes (Tan, 2011). However, their application requires heated equipment to liquefy molasses-like epoxy component and mixing with the catalyst must be done only at the nozzle. Properly designed systems are not only exceptionally durable, but also hard and flexible.

The hazards of all epoxy systems are numerous and start with the epoxy resin itself, which can initiate allergic reaction, general human toxicity of the starting materials for production of the resin, corrosive properties of the polyamine component, and either the need for heated 
equipment or slow drying. European Union is attempting to limit the use of epoxies due to human and environmental health considerations. ${ }^{4}$ Indeed, epoxy paints are seldom used in Europe.

Systems based on straight or modified polyurea or polyurethanes are in general principles similar to epoxy. Due to high pricing and human health considerations (the presence of isocyanates, which are known to cause allergic sensitisation), they are even more rarely used.
As compared to epoxy, durability of such systems tends to be better and they are less sensitive to ultraviolet radiation.

\subsection{Coldplastic}

Coldplastic is more of a class in itself, even though it is in a sense a plural component system. In coldplastics, monomers (most of the time various acrylates) are mixed with pigments and fillers and anti-skid materials and polymerised on the road surface to form exceptionally durable, hard, well-adhering marking. Schematic process is shown in Fig. 7.

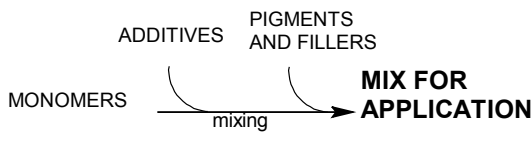

Fig. 7.

Coldplastic Process

Source: By Authors
To start the polymerisation, small amount of an initiator is added, which requires high dosing accuracy and specialised equipment. Coldplastics are quite sensitive to moisture and temperature, which mandates the use of special formulations and/or an accelerator or a retarder as needed. When properly applied, coldplastics dry within 20-30 minutes and with correctly selected glass beads provide high retroreflectivity. Coldplastics are used mainly on high-traffic roads and on pedestrian crossings (Asdrubali et al., 2013). They can be extruded at thick layers or as structured markings for lines and also applied by hand. The typical thickness is 2-5 $\mathrm{mm}$, which assures long service life.
Amongst major risks associated with the use of coldplastic, one must list the monomers, which are flammable and can undergo uncontrolled polymerisation. Another major risk is associated with the initiator, which requires special labelling and transportation. Due to these hazards, coldplastics, despite being versatile, having minimal environmental impact at the time of application, and offering excellent properties, cannot fulfil GPP requirements for ecologically-friendly product. Amongst human health considerations, it is quite interesting that while some people report the odour of acrylic monomers as pleasant and fruity, to others it is aggressively unpleasant

${ }^{4}$ First steps were taken to limit contact of epoxy materials with foods in Commission Directive 2002/16/EC (20.02.2002). 
and irritating. Commonly used butyl acrylate has the odour detection limit of mere $0.1 \mathrm{ppb}$ $\left(0.00052 \mathrm{mg} / \mathrm{m}^{3}\right)$. Human nose can detect butyl acrylate as a level about 1,000 times lower than the permissible exposure limit! (National Institute of Health). Hardly ever used polyester-based materials fall into this category.

\subsection{Road Markings Tapes}

These materials are available at several performance levels and types, both permanent and temporary. Tapes are typically applied by rolling onto hot or primed surfaces, or are at times placed in specially prepared grooves. High quality of surface preparation and application technique are of utmost importance. Glass beads are incorporated into the material during factory manufacturing, which leads to improved performance and retroreflectivities of up to $1000 \mathrm{mcd} / \mathrm{m}^{2} / \mathrm{x}$ can be achieved. High-end tapes have a service life longer than others marking systems.

These systems are expensive: In addition to very high cost of the tapes themselves, which can reach even $60 € / \mathrm{m}^{2}$, application could cost 5 to 10 times more than application of thermoplastic markings. ${ }^{5}$ Frequently, low-end tapes are used for temporary marking due to their relative ease of application and removal. Most, if not all of high-performance tapes are covered by patents assigned to $3 \mathrm{M}$ Corporation, which appear to hamper competitive development (Jones and Bredahl, 1980).

\subsection{Paints}

Paint remains the most widely used road marking material in the world since it

\footnotetext{
${ }^{5}$ Average price in Croatia between 2008 and 2014.
} Source: Authors. was first applied as a centreline in 1911 in Michigan, U.S.A. Paint application is done by simple spraying using high- or low-pressure equipment; it does not require heating or special technologically advanced application machines. Paints generally have good affinity for glass beads, which sometimes are premixed or more frequently dropped-on or injected to the wet film.

All paints are composed of the resin (historically, chlorinated rubber or alkyd resins were used; more recently styreneacrylic, acrylic-alkyd blends or $100 \%$ acrylic are preferred), pigments and fillers, solvents, and numerous additives.

Partially as a part of the worldwide movement to limit VOC emissions and to minimise the effects on human health and partially to seek improved performance, solventborne paints are slowly being replaced by waterborne paints or solvent-less road marking materials (Andrady, 1997; Mouton, 2010).

\subsubsection{Solventborne Paints}

Contemporary solventborne paints are based on acrylic resins (rarely styrenic- or alkydacrylic blends) that are dissolved in organic solvents like esters or ketones. In countries where it is still permitted, aromatic solvents are used despite their harmfulness for the environment and human health hazards (McMichael, 1988) - that is due to their lower price, better control of drying, and generally improved adhesion to asphaltic and oily surfaces. ${ }^{6}$ Low surface tension of

\footnotetext{
${ }^{6}$ (a) In Poland up to $2 \%$ of aromatic solvents are permitted per "Warunki Techniczne. Poziome znakowanie dróg. POD2006. Seria „I” - Informacje, Instrukcje.” IBDiM, Warszawa, 2007; (b) In the United States, "Federal Specification TT-P-115F (5.12.1985): Paint, traffic (highway, white and yellow)" does not limit the use of solvents and indeed, even xylenes are occasionally used (Source: Authors).
} 
solvents permits them to penetrate road surface cracks, which assures good adhesion of solventborne paints to road surfaces, even those in poor condition.

After application, evaporation of the solvent causes the polymer to solidify and thus the film forms, as a purely physical phenomenon, as shown schematically in Fig. 8. The solvent serves its purpose only to make the paint liquid and then escapes to the atmosphere as VOC, which in a typical high-solids solventborne road marking paint reaches $400-500 \mathrm{~g} / 1$ ( 25\%). It has been estimated that in European Union about 35,000 tonnes of VOC are annually emitted from solventborne road marking paints ("Review of directive 2004/42/EC.”, 2011).

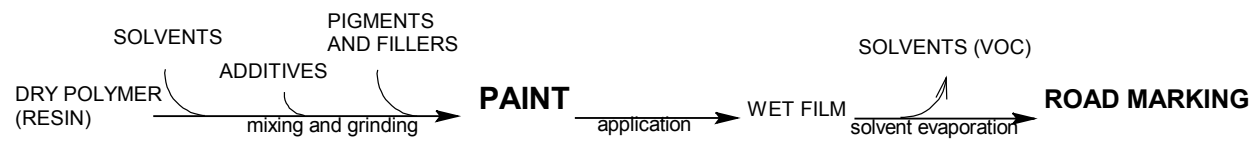

Fig. 8.

Solventborne Paints Process

Source: By Authors

In-can stability of solventborne paints is most of the time rather poor (stable formulations are quite rare in the market due to their high cost) - settling and thickening occur, but they can be easily alleviated by the users by mixing and addition of solvent. Application is typically done at wet film builds reaching only $400 \mu \mathrm{m}$; thicker films tend to form skin and take very long to dry, even at favourable conditions.

Application of solventborne paints can be done at air temperatures $5-40^{\circ} \mathrm{C}$ and surface temperature below $50^{\circ} \mathrm{C}$. The roadway must be clean, dry, and the temperature above dew point. Drying of such paints is strongly influenced by air and surface temperature, air movement, applied film build, and the utilised solvent blend. Humidity does not really affect solventborne paints and it has been seen that their application is stopped only when drizzle starts - this is their biggest advantage.
Solventborne paints are not suitable for high-volume roadways due to their poor durability: The expected service life on a side-line marking is only 6-12 months.

\subsubsection{Waterborne Paints}

Before waterborne paints are discussed, a property unique to them must be explained: washout resistance. The applied waterborne paint achieves washout when it no longer is affected by rain, which is later (in some cases much later) than dry-through. There is no standard protocol of measuring washout resistance time. Laboratory procedure where paint applied on a panel is exposed to running water, which is to imitate heavy rain, is frequently used. However, a method preferred by the authors is a water droplet - finger push-and-twist method: A drop of water is applied to paint surface for 1 minute and then finger with a set pressure is applied with twisting motion that is to 
imitate car tyres moving on the surface washout resistance is achieved when the paint is no longer affected by the action. Such test can be conveniently performed at the application site, too. Even though the method is subjective, it is quite reproducible with experienced user - for a more scientific laboratory alternative, one could utilise an instrument such as Dry Time Tester.

Washout resistance time very strongly depends on the utilised binder and additives and is affected by weather conditions, in particular humidity. Under normal dry conditions, there is no need to wait for paint to achieve washout resistance to open the road to traffic - this property is absolutely critical only when there is a risk of rain.

First waterborne road marking paints were commercialised in the 1980s. Those paints were quite similar to solventborne coatings in terms of solvent evaporation causing drying, but their main solvent was water. They suffered from sluggish drying and very slow development of washout resistance; hence, their use remained quite limited. On the other hand, very good durability, in-can stability, and quite low price made them a good option in certain areas, where they are still utilised.

The development of quick-set binders by Morton International in the early 1990s (Clinnin et al., 1991) recently lead to the success of waterborne paints in some markets. Generic process, shown in Fig. 9 from the starting materials to prepare the binder, is obviously more complex as compared to solventborne paints. The presence of carefully selected amine and high $\mathrm{pH}$ assure that the resin, containing acidic moieties in the backbone, does not precipitate in aqueous environment. Upon application, drop of $\mathrm{pH}$ occurs as ammonia evaporates and the polymer irreversibly solidifies. Hence, dried water-based paint cannot be re-dissolved in water or even in most common organic solvents. This physicochemical change of state is as major difference from solventborne paints as using water as the medium.

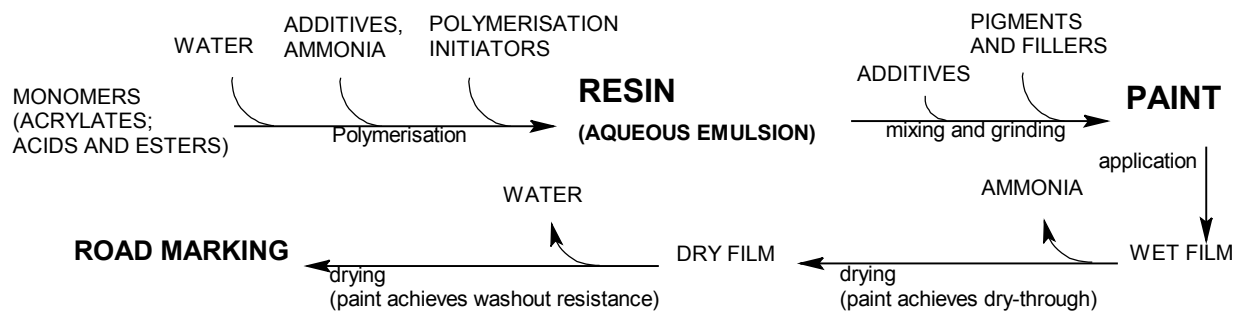

Fig. 9.

Waterborne Paints Process

Source: By Authors

From the quick-set technology comes a unique property of waterborne road marking paints - they stop being tacky very quickly. Clear distinction between tack-free, dry- through, and washout resistance times can be measured. For the applicator, quick tackfree time means lesser unsightly overdrive marks. 
Application at film builds reaching $900 \mu \mathrm{m}$ or more is possible without very significant slowing in drying (as mentioned above, solventborne paints applied at wet film builds higher than $400 \mu \mathrm{m}$ are not practical due to very dramatic increase of dry-through time). Application of sandwich systems is also feasible with waterborne paints.

VOC content of a typical waterborne road marking paint is less than $50 \mathrm{~g} / 1(\sim 2 \%)$, coming from the required additives. Properly designed waterborne paints have shelf life of about one year - no settling or skin formation should occur during storage and the paint is ready to apply as delivered. Minor viscosity increase is normal and the paints can be thinned by the applicators with a tiny amount of water. Paint has to be protected from frost and extreme heat, though. ${ }^{7}$

The same equipment and procedures as are utilised for application of solventborne paints can be followed, with two caveats: to avoid rusting only stainless steel equipment is allowed and the paint cannot be permitted to dry in the equipment (which forces the applicators to maintain clean work environment).

Waterborne road marking paints are reported as compatible with a variety of surfaces, including bituminous and concrete materials. As with all other materials, they show sensitivity to freshly applied concrete or asphalt. Waterborne paints generally adhere well to the existing markings independently on their type, even to thermoplastic masses, which made them excellent choice for marking renewal.

\footnotetext{
${ }^{7}$ United States specifications require freeze-thaw and heat stability (Cf. TT-P-1952E.). In Europe, there is no freeze-thaw requirement and the heat stability demands are less strict (Cf. specification EN 1871).
}

\section{Characteristics and Application of Waterborne Road Marking Paint - General Considerations}

Waterborne road marking paint is commonly used in the United States - not really because of its environmental friendliness as it is a country where acetone or a fluorinated and chlorinated aromatic compound are not considered VOC (sic!), but due to excellent cost-performance balance. ${ }^{8}$ In Europe, waterborne paints are used in Scandinavia, where solventborne paints are banned, and also in France, Italy, Spain, and to a limited extend in a couple lands in Germany. Other European countries use mostly, if not solely, paints based on organic solvents.

Amongst the advantages of waterborne road marking materials one must first list their environmental friendliness. A cradleto-grave Life Cycle Analysis (LCA) was prepared and presented by Dow, major manufacturer of the binders for waterborne paints, where in all of the measured LCA categories, waterborne paints were presented as winners (Kheradmand, 2012). Simultaneously, manufacturer of monomers for coldplastic, Evonik, presented their LCA showing advantage of their product (Klein, 2012). The authors herein do not assess truthfulness of either analysis.

For the contractor applying road markings, the advantage of using waterborne paint is the absence of hazardous and flammable ingredients, which can lead into lower transportation and storage costs. However, a disadvantage is that the paint must be protected from frost and extreme temperature. At the application time, advantages and disadvantages of waterborne road marking materials are ambiguous.

${ }^{8}$ Per 40 CFR 51.100. 
Drying at favourable conditions can be much faster as compared to solventborne materials (see Table 2 below), but simultaneously at unfavourable humid conditions or in case of sudden rain there is a risk of washout. Hence, the applicators must be properly trained and must understand the limitations of the systems: vide Scandinavia, where rain is frequent and hot-dry conditions essentially absent and there are no problems with waterborne paints.

For the road authorities, advantages of waterborne paints are numerous: faster drying at proper conditions means lesser traffic congestion, higher durability means lower overall road maintenance cost, and the environmental friendliness means lower impact on our and our planet's health. The environmental impact should be considered particularly in cities suffering from high ground-level ozone. The disadvantage is slightly higher immediate price tag that must be paid - even though long-term performance balances the initial cost.

One must remember that there are several qualities of waterborne paints and it would be unfair to compare the low-end material with, for example, coldplastic - especially at different applied film builds (Montebello and Schroeder, 2000). Similarly, some documents lists waterborne paints as having no pick-up times of up to 15 minutes, dry-through of up to 1 hour - that is all true, but does not fully apply to modern fast-dry paints.

Durability in the field is typically measured by retroreflectivity. This is affected by the utilised glass beads, weather conditions at the application site, application technique, road surface quality, etc. High durability of waterborne paints is expected, based on their chemistry. Indeed, in a study done by Dow at an application site in Pennsylvania, U.S.A., a high-end waterborne paint applied at 600 $\mu \mathrm{m}\left(900 \mathrm{~g} / \mathrm{m}^{2}\right)$ wet film build (about 400 $\mu \mathrm{m}$ dry film) was reported to outperform a thermoplastic road marking material applied at $3000 \mu \mathrm{m}$ (Randazzo, 2013)!

\section{Characteristics and Application of Waterborne Road Marking Paint - Application in Croatia}

Recently, a field application was done on a heavily travelled two-lane Croatian road to assess (1) feasibility and ease of applying waterborne road marking paints in Croatia, (2) evaluate the paints' performance, and (3) test various glass beads for retroreflectivity and its retention under normal use conditions.

The selected road stretch near Zagreb is travelled by approximately 8000 vehicles per day, has two years old asphalt in good condition, and was marked with the standard solventborne paint commonly utilised in Croatia. The application work was done by crew from Chemosignal d.o.o. (Zagreb, Croatia), under the direction of Faculty of Transport and Traffic Science, Department for Traffic Signalization (University of Zagreb), using two waterborne paints from Swarco Limburger Lackfabrik GmbH (Diez, Germany) and drop-on reflective materials from M. Swarovski GmbH (Amstetten, Austria).

The application crew has never worked with waterborne paints, but was experienced with solventborne paints and other road marking materials. After a few adjustments of the machinery (pressure, nozzle, etc.) the waterborne paints were applied without difficulties at target wet film builds $400 \mu \mathrm{m}$ and $600 \mu \mathrm{m}$. Changes of paint and layer 
thickness were accomplished effortlessly, but tuning of the machine was necessary each time. Lesser required coning and absence of the tyre marks from vehicles driven by careless and impatient drivers encroaching on the freshly marked lines were noted. Accidentally, the crew run out of paint and that lead to initiation of paint drying in the drum and flow difficulties - immediate cleaning of the filters solved the problem. There were no issues with drop-on glass beads; their embedment was visually good. (A little curiosity must be noted here: The utilised small American-made application machine has a container for glass beads holding only $49 \mathrm{~kg}$ of beads, so two full bags did not fit!) Side and centre lines were marked at the standard width of $15 \mathrm{~cm}$; each system was applied at 500-m stretch.

Drying and washout times shown in Table 2 were achieved in the field. The weather conditions were perfect: mostly sunny with mild wind, roadway temperature $30-45^{\circ} \mathrm{C}$ and air temperature $20-28{ }^{\circ} \mathrm{C}$ at $40-60 \%$ relative humidity.

\section{Table 2}

Drying and Washout Resistance of Various Road Marking Materials during Application near Zagreb

\begin{tabular}{llll}
\hline Road marking material & $\begin{array}{l}\text { Applied wet film } \\
\text { build }\end{array}$ & $\begin{array}{l}\text { Dry-through Washout } \\
\text { resistance }\end{array}$ \\
\hline Swarco Limboroute Aqua W13, fast-dry waterborne paint & $400 \mu \mathrm{m}$ & $4 \mathrm{~min}$. & $8 \mathrm{~min}$. \\
Swarco Limboroute Aqua W15, high-performance waterborne paint & $400 \mu \mathrm{m}$ & $10 \mathrm{~min}$. & $22 \mathrm{~min}$. \\
Swarco Limboroute Aqua W15, high-performance waterborne paint & $600 \mu \mathrm{m}$ & $15 \mathrm{~min}$. & $36 \mathrm{~min}$. \\
Two standard solventborne high-solids paints & $400 \mu \mathrm{m}$ & $17 \mathrm{~min}$. & - \\
\hline
\end{tabular}

Source: By Authors

While retroreflectivity is used to measure quality of the road marking, durability of the paints themselves can be assessed in the laboratory using Taber abrasion, according to ASTM C1353 procedure. Fig. 10 illustrates durability achieved with the road marking materials that were applied near Zagreb. Poor performance of the high-solids solventborne $100 \%$ acrylic paint is obvious - the reported data represents average of two solventborne paints and duplicate results. The result of this on the road should be visible after loss of glass beads, which in addition to providing retroreflectivity serve to protect the paint. 


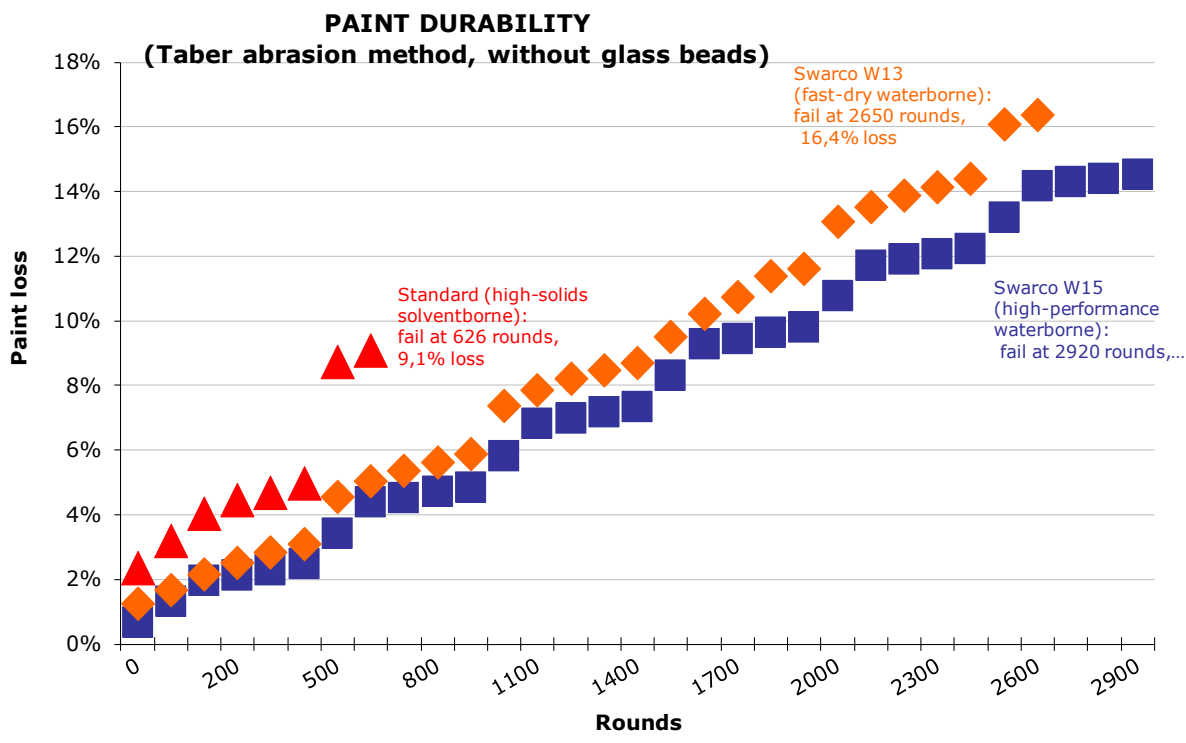

Fig. 10.

Taber Abrasion Testing of Paint Durability (600- $\mu \mathrm{m}$ Drawdowns), Without Glass Beads Source: By Authors

Initial retroreflectivity, measured two weeks after application, depended on the film build and glass beads type and size. Three months after application, surprisingly increased retroreflectivity of waterborne paints as compared to initial was measured in some cases. Quite possibly, the time to develop maximum retroreflectivity may be longer in case of waterborne paints than is commonly accepted. ${ }^{9}$

\footnotetext{
${ }^{9}$ According to German rules described in ZTV M 13, full development of retroreflectivity occurs in exactly 12 days.
}

Retroreflectivity was measured using both dynamic and static test methods. The dynamic method, using retroreflectometer installed on a vehicle, is collecting data all the time (in milliseconds) and delivers average value every 25 meters. Data collection is done during normal driving at speeds up to $130 \mathrm{~km} / \mathrm{h}$. Static measurements are done traditionally, using handheld retroreflectometer. It is definitely much too early for conclusions, so only selected data is provided in Table 3. The initial results meet our expectations. 
Table 3

Dynamic Measurements of Retroreflectivity, Centre Line

\begin{tabular}{lllll}
\hline Paint & $\begin{array}{l}\text { Applied wet } \\
\text { film build }\end{array}$ & $\begin{array}{l}\text { Glass beads type } \\
\text { and size range }(\mu \mathrm{m})\end{array}$ & \multicolumn{2}{l}{$\begin{array}{l}\text { Retroreflectivity }(\mathrm{mcd} / \mathrm{m} 2 / \mathrm{lx})- \\
\text { Initial }\end{array}$} \\
\hline W15 & $600 \mu \mathrm{m}$ & Megalux-Beads ${ }^{\circledR} 600-1400$ & 423 & 582 \\
W15 & $600 \mu \mathrm{m}$ & Swarcolux50 212-1400 & 379 & 404 \\
W15 & $400 \mu \mathrm{m}$ & SolidPlus100 212-850 & 677 & 671 \\
W15 & $400 \mu \mathrm{m}$ & SolidPlus30 300-1000 & 516 & 383 \\
W13 & $600 \mu \mathrm{m}$ & Swarcolux50 212-1400 & 440 & 424 \\
W13 & $400 \mu \mathrm{m}$ & SolidPlus100 212-850 & 645 & 442 \\
Solventborne & $400 \mu \mathrm{m}$ & Swarcolux50 200-800 & 538 & 384 \\
\hline
\end{tabular}

Source: By Authors

\section{Conclusions}

Waterborne road marking paints appear a viable alternative to the currently utilised solventborne paints with possibility to encroach onto the markets currently occupied by more durable systems. Durability of waterborne paints, measured by Taber abrasion, is outstanding and significantly outperforms the compared standard solventborne materials. The measured drying and washout resistance times were excellent under favourable conditions at application time: waterborne paints dried significantly faster than comparable solventborne materials. The caveat is the risk of washout in case of sudden downpour and inferior drying at low temperature high humidity conditions. Adhesion of glass beads appears enhanced as compared to solventborne paints, as evidenced by better retention of retroreflectivity, but the results from the test application are too fresh to draw positive conclusions.

From the point of view of application, waterborne paints can be applied effortlessly as long as the personnel is appropriately trained and maintains clean work environment. During the test application work in Croatia, the crew was satisfied; they noticed and praised quick drying during the good weather at the application time.

With the use of waterborne road marking paints, absence of hazardous, flammable, and toxic chemicals and lower emissions benefit our and our planet's health. For the road authorities, the use of waterborne paints would mean somewhat higher initial cost that should be offset by longer usable paint life and lesser social health costs. In addition, quick drying under good conditions would permit lesser road blocking and easing traffic congestion.

Testing of retroreflectivity shall be done periodically - the initial results reported herein are meeting and exceeding our expectations (Babić et al., 2014).

\section{References}

Andrady, L. 1997. Pavement marking materials: assessing environment friendly performance, Transportation Research Board, ISBN 0309060648.

Asdrubali, F.; Buratti, C.; Moretti, E.; D’Alessandro, F.; Schiavoni, S. 2013. Assessment of the Performance of Road Markings in Urban Areas: The Outcomes of the CIVITAS RENAISSANCE Project, The Open Transportation Journal. DOI: http://dx.doi.org/10.217 4/1874447801307010007, 7: 7-19. 
Babić, D.; Burghardt, T.; Prusa, P. 2014. Application and characteristics of waterborne road marking paint. In Proceedings of the International Conference on Traffic and Transport Engineering, Belgrade. 265-274.

Bosley, C. 2007. Town ditches traffic lights to cut accidents, Reuters.

Clinnin, D.D.; Heiber, W.G.; Lewarchik, R.J. 1991. Fast dry waterborne traffic marking paint. Patent US5340870.

Clare, R.S. 2015. Traffic Safety. Available from Internet: <http://www.rsclare.com/sites/default/files/ Traffic\%20Safety.pdf $>$.

Dwyer, C.E.; Vavrik, W.R.; Becker, R.L. 2013. Evaluating Pavement Markings on Portland Cement Concrete (PCC) and Various Asphalt Surfaces. Report ICT-R27-077. Illinois Center for Transportation.

Eby, D.W.; Molnar, L.J.; Kartje, P.S. 2008. Maintaining Safe Mobility in an Aging Society. CRC Press, ISBN 1420064541.

European Commission. 2010. Communication from the Commission to the European Parliament, the Council, the European economic and social committee and the Committee of the regions. Towards a European road safety area: policy orientations on road safety 20112020, Brussels, Belgium, July 2010. Available from Internet: <http://ec.europa.eu/transport/road_safety/ pdf/com_20072010_en.pdf $>$.

European Road Statistics. 2013. European Union Road Federation.

Gates, T.J.; Hawkins, H.G.; Rose, E.R. 2003. Effective pavement marking materials and applications for Portland cement concrete roadways. Report 4150-2: Evaluation of Pavement Marking Effectiveness. Texas Department of Transportation, Texas Transportation Institute.
Grosges, T. 2008. Retro-reflection of glass beads for traffic road stripe paints, Optical Materials. DOI: http:// dx.doi.org/10.1016/j.optmat.2007.09.010, 30(10): 1549-1554.

Hamilton-Baillie, B.; Jones, P. 2005. Improving traffic behaviour and safety through urban design. In Proceedings of the ICE - Civil Engineering. DOI: http:// dx.doi.org/10.1680/cien.2005.158.5.39, 158(5):39-47.

Horberry, T.; Anderson, J.; Regan, M.A. 2006. The possible safety benefits of enhanced road markings: a driving simulator evaluation, Transportation Research Part F: Traffic Psychology and Behaviour. DOI: http://dx.doi. org/10.1016/j.trf.2005.09.002, 9(1): 77-87.

Jones, D.C.; Bredahl, T.D. 1980. Incorporating a porous fibrous web embedded in a pressure sensitive adhesive layer. Patent US4299874.

Kheradmand, H. 2012. Life Cycle Assessment. Road Marking Technologies Eco-Profile, Intertraffic, Amsterdam.

Klein, A. 2012. Lifecycle under the lens, Intertraffic World, Annual Showcase, Infrastructure, 210 p.

McMichael, A.J. 1988. Carcinogenicity of benzene, toluene and xylene: epidemiological and experimental evidence, IARC Scientific Publications, 85: 3-18

Migletz, J.; Fish, J.; Miles, J. 1994. Roadway Delineation Practices Handbook, U.S. Dept. of Transportation, Federal Highway Administration, Washington, D.C., U.S.A., Tech. Rep. FHWA-SA- 93-001.

Migletz, J.; Graham, J.; Bauer, K.; Harwood, D. 1999. Field Surveys of Pavement Marking Retroreflectivity, Transportation Research Record. DOI: http://dx.doi. org/10.3141/1657-10, 1657: 71-78.

Miller, T.R. 1992. Benefit-cost analysis of lane marking, Transportation Research Record, 1334: 38-45. 
Montebello, D.; Schroeder, J. 2000. Cost of Pavement Marking Materials, Final Report, Minnesota Local Road Research Board.

Mouton, Y. 2010. Organic Materials in Civil Engineering, John Wiley \& Sons, ISBN 0470394501.

National Institute of Health, U.S. National Library of Medicine TOXNET database.

Randazzo, C. 2013. Waterborne Traffic Markings Technology and Testing, Dow Coating Materials.

Retting, R.A.; McGee, H.W.; Farmer, C.M. 2000. Influence of Experimental Pavement Markings on Urban Freeway Exit-Ramp Traffic Speeds, Transportation Research Record. DOI: http://dx.doi.org/10.3141/170517, 1705: 116-121.

Review of directive 2004/42/EC. 2011. Oekopol GmbH, Institute for Environmental Strategies. Stockholm.
Tan, L. 2011. Composition of polyacrylate, epoxy and polyamine. Patent US20120214908.

Thurston, P. 2009. Pavement Markings Role in Enhancing Road Safety Strategies, Roadmarking Industry Association of Australia.

Towards a European road safety area: policy orientations on road safety 2011-2020. 2010. Communication From The Commission To The European Parliament, The Council, The European Economic And Social Committee And The Committee Of The Regions. $\operatorname{COM}(2010)$ 389. Brussels.

Zwahlen, H.T.; Schnell, T. 1998. Visibility of Road Markings as a Function of Age, Retro-reflectivity Under Low-beam and High-beam Illumination at Night, Paper No. 980285, presented at the 77th Annual Meeting of the Transportation Research Board, Washington, D.C. 